\title{
A LEAD-RUBBER SHEAR DAMPER
}

\author{
W. H. Robinson and A. G. Tucker*
}

\section{ABSTRACT}

A lead-rubber damper consisting of a steel-reinforced elastomeric bearing with a lead insert fitted in its centre has been tested at earthquake-like frequencies $(0.9 \mathrm{~Hz})$ with a vertical load applied. For an engineering shear strain of \pm 0.59 , the damper completed 340 cycles and operated satisfactorily at temperatures of $-35+5^{\circ} \mathrm{C}$ and $45+5^{\circ} \mathrm{C}$. We believe that the lead-rubber damper is suitable for installing in base-isolation systems for the protection of buildings and bridges during earthquakes.

\begin{abstract}
Recent studies by Skinner, Beck and Bycroft(1) have shown that mounting a building or bridge on a combination of horizontally flexible mounts and hysteretic dampers can drastically reduce the effect of earthquake attack. This system of mounting a structure has been called base isolation. Previous work in our laboratory has resulted in the invention of hysteretic dampers using steel (Skinner, Kelly and Heine $(2)$ ) and of lead extrusion dampers (Robinson and Greenbank $(3,4)$, all capable of absorbing the energy of motion of a structure during many earthquakes. Twenty $420 \mathrm{kN}$ steel dampers are being installed in a 300 metre New zealand Railways' bridge, and twelve $140 \mathrm{kN}$ extrusion dampers are being placed in two of the Ministry of Works and Development bridges over the Wellington motorway. These dampers were manufactured under licence by ANAC of Auckland. In this paper we describe a leadrubber shear damper(5) suitable for use in base isolation systems, and discuss some of the tests we have carried out on the damper.
\end{abstract}

The lead-rubber shear damper was constructed by taking a 356 x 356 x $140 \mathrm{~mm}$ bonded elastomeric bridge bearing, containing seven $3 \mathrm{~mm}$ thick steel plates and six $16 \mathrm{~mm}$ rubber plates, drilling a hole through its centre (diameter order of $100 \mathrm{~mm}$ ), and filling the hole with a lead insert (Fig. 1). The resulting lead-rubber shear damper was then bolted into a dynamic test rig driven by a Caterpillar D8 which was capable of supplying $100 \mathrm{~kW}$ at the damper, at up to $500 \mathrm{kN}$ with a maximum frequency of $0.9 \mathrm{~Hz}$ and

maximum total stroke of $136 \mathrm{~mm}$. The vertical load applied to the damper, which represented the weight of the structure, could be varied from zero to $450 \mathrm{kN}$. A total of 70 tests under varying conditions of vertical load, stroke, cycle frequency and temperature were conducted. A summary of the tests at 400 $\mathrm{kN}$ vertical load and $0.9 \mathrm{~Hz}$ are shown in Table 1. These tests have demonstrated that lead-rubber dampers should perform satisfactorily during a number of successive major earthquakes and also during the many small movements caused by wind or thermal expansion.

The resulting force displacement diagram

* Materials Science Section, Physics and Engineering Laboratory, Department of Scientific and Industrial Research, Lower Hutt. obtained for the rubber alone and for the lead-rubber damper is shown in Fig. 2. In this figure the force $F^{\prime}$ is that for the rubber alone at the manufacturers maximum recommended engineering shear strain, $\gamma$, of 0.5 . A convenient performance factor for a hysteretic damper is the ratio of its hysteresis loop area to the area of a circumscribing rectangle with sides parallel to the co-ordinate axis, since this compares the damper with an ideal rigid-plastic device. The corresponding performance factor for a damper which includes an elastic bearing is qiven by the ratio of its loop area to the area of the circumscribing parallelogram which has sides parallel to the axis of the rubber loop and to the force ordinate. For the lead-rubber damper tested, the performance figure was 0.67 .

As can be seen in Figure 2 the hysteresis loop can be approximated by a parallelogram passing through points $a, b$ and $c$. The area of the parallelogram is 0.98 times that of the hysteresis loop while the sides of the parallelooram are close to the slopes of the loop. A summary of the characteristics of the lead-rubber damper for a maximum shear strain of $\gamma=0.53$ is included in Table 2. The value of $F(a) / F$ (vert) of 0.128 for $\gamma=0.53$ is close to the figure of $12 \frac{1}{2} \frac{\circ}{\circ}$ for $\gamma=0.5$ which has been suggested $(2)$ for an effective base isolation system.

The good performance of the damper is most likely due to the fact that at its operating temperature the lead is being "hot worked" so that during its deformation the lead recovers most of its mechanical properties almost immediately. Furthermore, all of the lead confined by the steel and rubber plates is forced to undergo pure shear rather than just part of it deforming in simple shear.

The lead-rubber damper has many features which suit it for use in a base isolation system. The primary function of the rubber bearing is to control the strain pattern of the lead, forcing it to deform in pure shear, and hence the damping characteristics of the device. However, the bearing also provides a horizontally flexible mount and an elastic centring force, both of which are required for most of the base isolation system studied. Moreover, it is convenient to construct lead-rubber dampers which 
provide the three features, hysteretic damping, lead bearing capacity and centring force, in proportions appropriate to a wide range of base isolation systems.

\section{REFERENCES}

1. R. I. Skinner, J. L. Beck and G. N. Bycroft, Int. J. Earthq. Engng. Struct. Dyn. 3, 297-309 (1975)

2. R. I. Skinner, J. M. Kelly and A. J. . Heine, Int. J. Earthq. Engng. Struct.
Dyn. 3, 287-296 (1975).

3. W. H. Robinson and L. R. Greenbank. Int. J. Earthq. Engng. Struct. Dyn. 4, 251-259 (1976).

4. W. H. Robinson and L. R. Greenbank, Bulletin N.Z. Soc. Earthq. Engng. 8, 187-194 (1975).

5. W. H. Robinson, N.Z. Provisional Patent No. 178949 .

Paper received 21 July, 1977.

TABLE 1

SUMMARY OF TESTS CONDUCTED AT $0.9 \mathrm{~Hz}$ WITH A $400 \mathrm{kN}$ VERTICAL LOAD

\begin{tabular}{|l|c|c|c|c|}
\hline \multicolumn{1}{|c|}{ Test No. } & Stroke/mm & $\gamma$ & Temp $/{ }^{\circ} \mathrm{C}$ & No. of Cycles \\
\hline 25,30 & \pm 68 & 0.58 & +15 & 3,5 \\
33 & \pm 62 & 0.53 & +15 & 5 \\
36 & \pm 48 & 0.41 & +15 & 5 \\
53 & \pm 2 & 0.01 & +15 & 10,000 \\
54 & \pm 68 & 0.58 & $+45 \pm 5$ & 10 \\
58 & \pm 68 & 0.58 & $-15 \pm 2$ & 5 \\
59 & \pm 68 & 0.58 & $-35 \pm 5$ & 5 \\
$62,64,65,66$ & \pm 68 & 0.58 & +15 & $20,50,100,50$. \\
69,70 & +115 & +0.99 & +15 & 65,20 \\
\hline
\end{tabular}

TABLE 2

SUMMARY OF PROPERTIES OF LEAD-RUBBER DAMPER

\begin{tabular}{|c|c|c|c|c|c|}
\hline Co-ordinates & $F^{\prime} / F^{\prime}$ & $F / F(v e r t)$ & $\gamma$ & $\begin{array}{c}\text { Stiffness } \\
\left(\partial\left(\mathrm{F} / \mathrm{F}^{\prime}\right) / \mathrm{\gamma}\right)\end{array}$ & $\begin{array}{c}\text { Stiffness } \\
(\mathrm{kN} / \mathrm{mm})\end{array}$ \\
\hline $\mathrm{a}$ & 1.76 & 0.128 & 0 & $\mathrm{a}-\mathrm{b}=3.4$ & 0.85 \\
$\mathrm{~b}$ & 3.56 & 0.258 & 0.53 & $\mathrm{~b}-\mathrm{d}=24$ & 6.0 \\
$\mathrm{c}$ & 0.86 & 0.062 & 0.42 & $0-\mathrm{c}=2.00$ & 0.50 \\
$\mathrm{~d}$ & 0 & 0 & 0.38 & $0-\mathrm{d}=0$ & 0 \\
\hline
\end{tabular}

Size $=356 \times 356 \times 140 \mathrm{~mm} \quad$ Mass $=82 \mathrm{~kg}$

$F^{\prime}=$ Force exerted by rubber at a strain of $0.5=29 \mathrm{kN}$

$F($ vert $)=13.8 \mathrm{~F}^{\prime}=400 \mathrm{kN}$

Design Stroke $(\gamma=0.5)= \pm 58 \mathrm{~mm}$ 

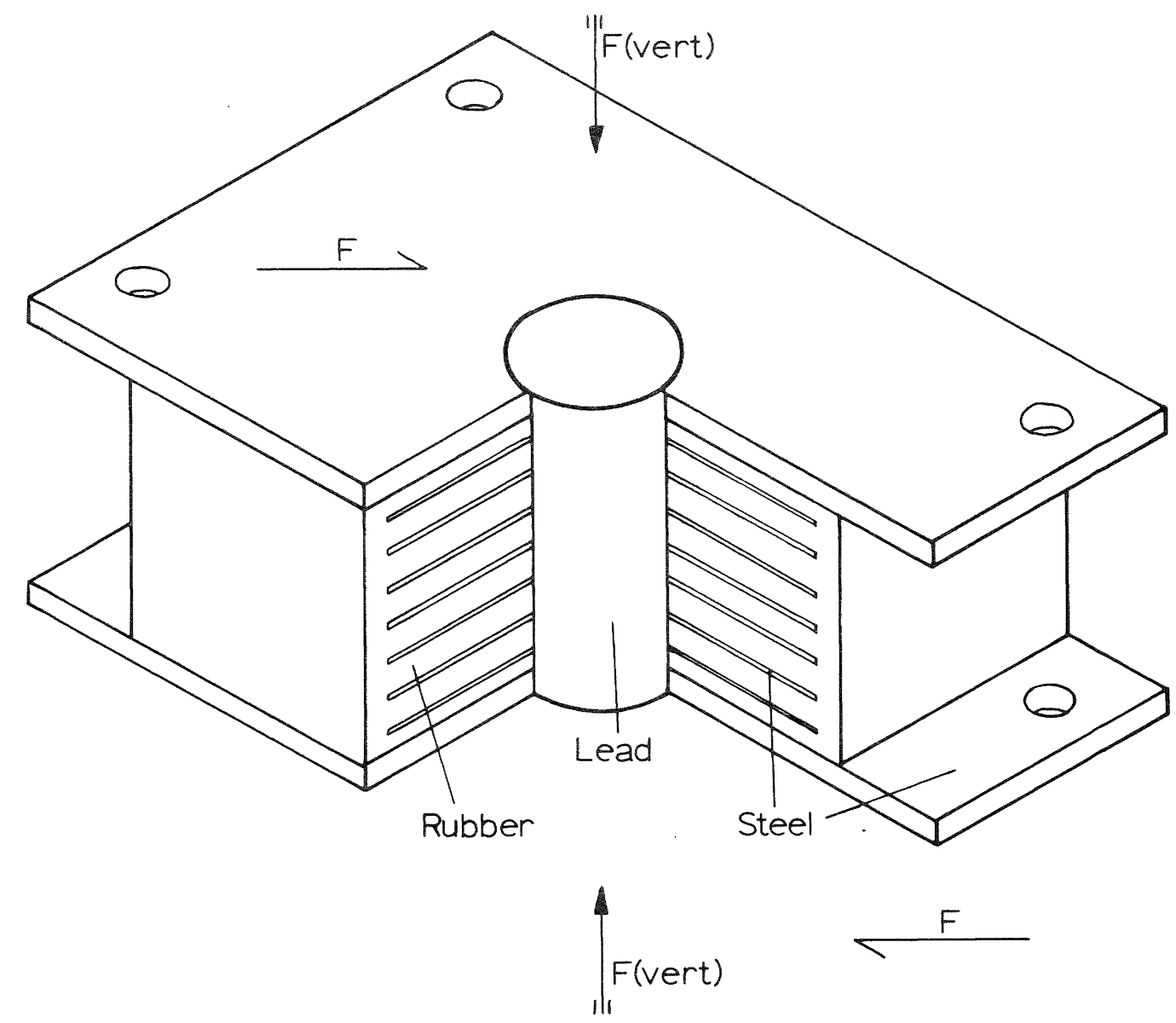

FIGURE 1: LEAD-RUBBER SHEAR DAMPER

Stroke/mm

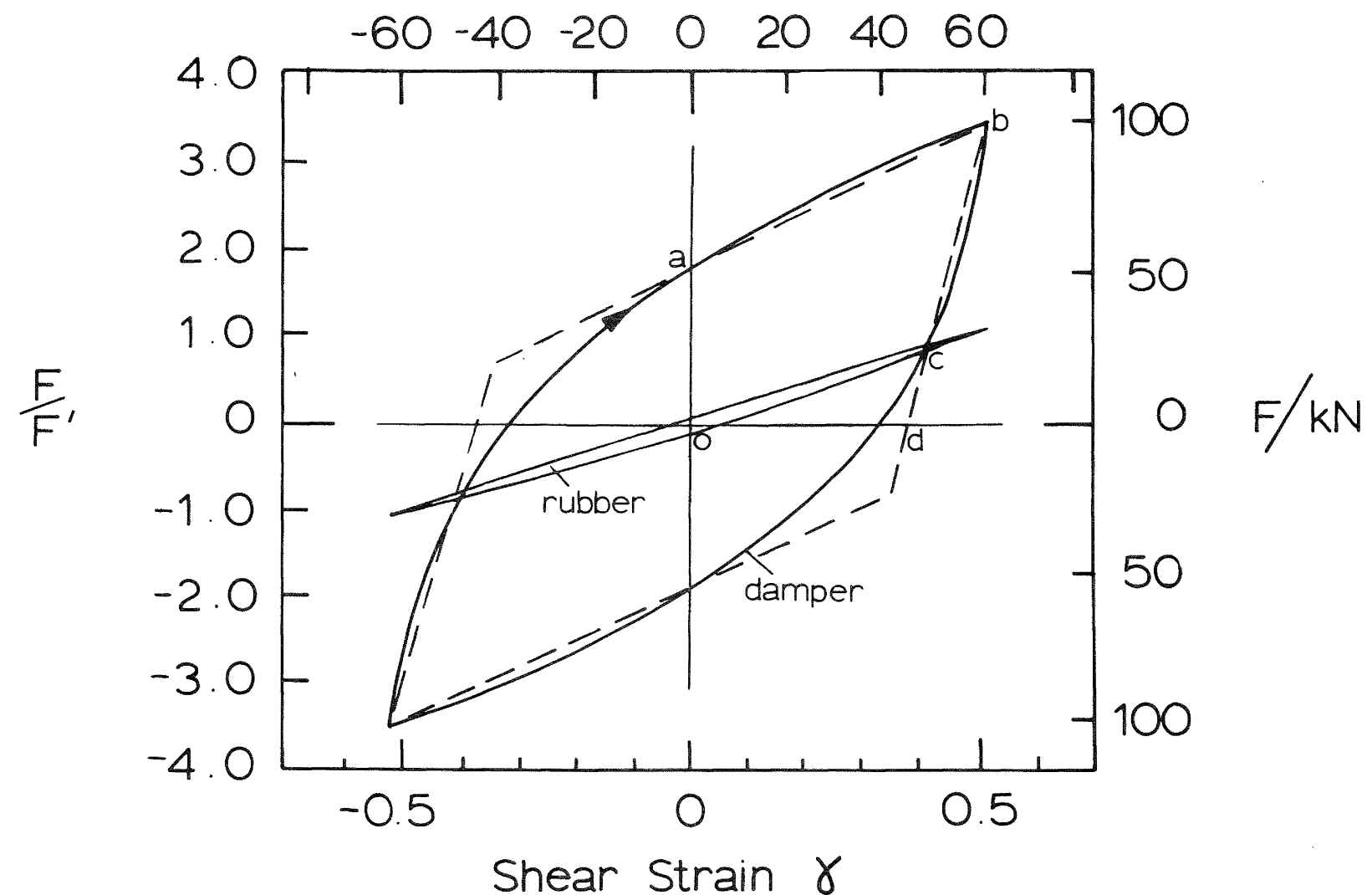

FIGURE 2: FORCE DISPLACEMENT CURVE OBTAINED 